\title{
Mechatronics Engineering Methodology of systemic codification of logical formal reasoning, in solving applied problems.
}

\author{
Pedro Ramiro Brito Portero \\ Center Research and Technology Transfer, Mechatronic Engineering, \\ International University of Ecuador, “UIDE”, Quito, Ecuador \\ rbrito@internacional.edu.ec
}

\begin{abstract}
The logic is one of the formal reasoning tools most subjects of the career of Mechatronics Engineering, especially of those that are more related to mathematics and programming. The use of a formal systemic coding promotes the definition of modern structured in different levels of abstraction, and facilitates the reasoning assigning a technically operational semantics to express the solution to problems applied models. This paper reports an investigation in this regard, specifically oriented to demonstrate the existence of any relationship between the intervention activities problem solving and structuring the creative logical thinking, presenting a methodological, didactic, playful, creative and cutting-edge procedure, called "logical process" easy to learn and manipulate, allowing express or design in a technical manner and precise solution is found in the brain.
\end{abstract}

Keywords - systemic Coding; Formal reasoning; Creative Logical thinking; Logical process

\section{INTRODUCTION}

"Logic is a formal science, has no content, but simply studies the valid forms of inference" [1].

All sciences have a logical representation in the solution to the various problems within the professional context, in order to understand this proposal, contrasting with some professions will be held:

The architect receives a problem, the same to the brain and is analyzed, challenged to find the right solution, at that moment when you already have the solution in the brain, it has to be expressed in a technical manner using a logical methodology I work called MAP, to conclude with the construction of the study object: a house, a building, etc.

Electronic Engineer receives a problem, the same to the brain and is analyzed, challenged to find the right solution, at that moment when you already have the solution in the brain, it has to be expressed in a technical manner using a logical methodology called DIAGRAM ELECTRONIC work, concluding with the construction of the object of study: a radio, a television, a computer, etc.

Engineer in the case study and professor of Logic Programming, receives a problem, the same to the brain and is analyzed, challenged to find the right solution, at that moment when you already have the solution in the brain this has to be expressed in a technical manner, using the methodology proposed in this research called logical process, concluding with the construction of the object of study: management system.

\section{Purpose AND Motivation}

The object is to present a new methodology for formal reasoning or valid, fun and educational logical process called inference, considering that logic studies the problems and laws of formal thought, important components for all sciences.

In the process of implementation and evaluation of curriculum projects aimed at training of engineers, and the same exercise of superior teaching it has allowed me to know the different features in the cognitive development of students, valid support to create strategies work permit enhance thinking with recreational and educational activities, and this research is emerged and with the active participation of students who corroborated the success of it, both academically and personally.

\section{CONTEXT}

Within the essence of logic programming as important in the design and interpretation of knowledge in different solutions to problems applied components are the flowcharts, diagrams boxes, Pseudocode; among others, technical or fundamental strategies for students entering engineering career in the chair of Logic Programming, the same that have been used for several decades, being currently outdated. In the era of knowledge, should make proposals to be according to scientific and technological progress, in other words, the logical process detailed in this investigation, meets all the essential features to be efficient, aesthetic, simple and fun, allowing students to acquire skills and learning-oriented solution to immediately enter the declarative and functional programming, using any programming language. 


\section{ORiginal Contribution}

The logical process is a neuro-cognitive semantic model that allows students of the subject of Computer Engineering career I Mechatronics Engineering, technically express the solution of any problem raised from the memory of the human brain; to the paper, using logical tools.

\section{METHOD}

The methodology used for the management of the project, was based from the experimental design based on the Aristotelian theory: where two types of knowledge, a practical, directed towards the production of innovations or practices formulations and other intellectual oriented knowledge is generated.

This methodological basis was considered as A CASE STUDY implemented in the laboratories of the Faculty of Mechatronics Engineering International University of Ecuador UIDE in the semester October to March 2017 in the course of Computer Engineering I, working with students I semester Mechatronics Engineering, he allowed to validate the methodology, and recognize the neuro-cognitive abilities that were generated at the end of the process, identified and assessed by the ability of development of multiple Intelligences. The research process was organized in two milestones:

a) Design and implementation of the teaching methodology LOGICAL PROCESS (use of logical tools).

b) Their heavy weight Validation of the teaching methodology logical process.

The experimental method allows feedback of knowledge up to the implementation of the neuro-cognitive methodological strategy called logical process begins with an analysis of a real problem, for which, neurons are not separate, but act with each other generating a network model.This schematic structure of neurons, is identified as a neural circuitry, the same as a set of linked neurons functionally and cognitively throughout the nervous system and assume the task of providing a correct answer.This response product synapse, technically be expressed as a visual model called logical process.

The use of the logical process, allows the student to develop recreational and cognitive skills in the field of mechatronics, starting from a fundamental and conceptual analysis up to generate a visual model that represents the solution to problems applied in the course of Computer Engineering I.

\section{PARTICIPANTS}

The methodology of the logical process, was implemented in the laboratories of Systems Engineering Faculty of the International University of Ecuador UIDE in the half October to March 2017, working with students in the I semester of Engineering, allowing validate the student's development recreational and cognitive in the field of logic, based on the descriptive and conceptual analysis up to generate a visual model that represents the solution to problems applied in the subject of logic programming skills.

\section{MATERIALS}

\section{A. Rules}

To start working with the logical process, take into account the following rules:

- All logical tools must be written in capital letters and printing.

- The logical solution must be synthetic, hierarchical and structured, margins should respect and follow a hierarchy of solution.

Solution Margin

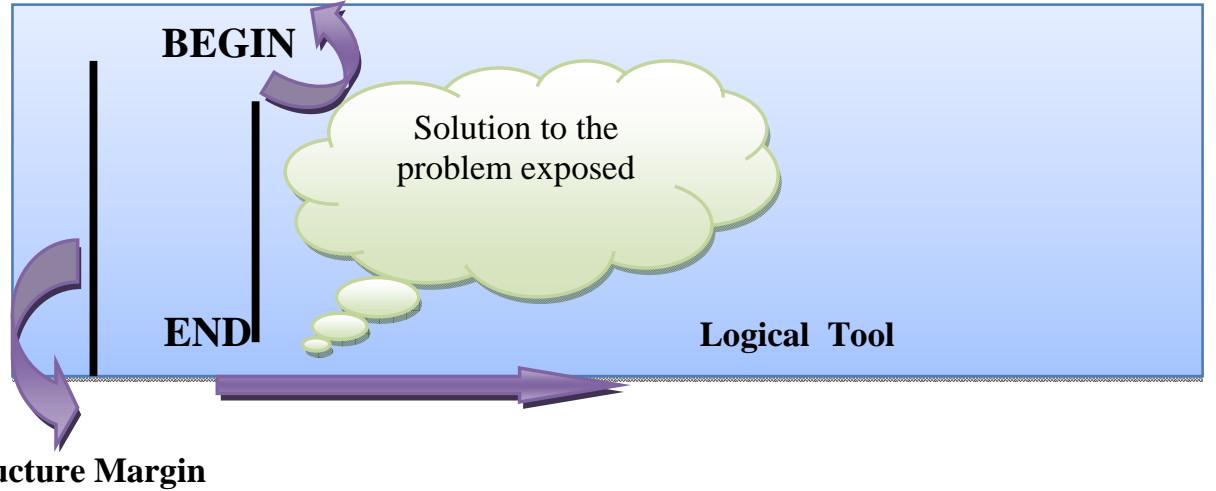

Fig. 1. General structure of Logical Process 


\section{B. Tools Logical Process}

1) BEGIN tool: In any process, you always have to specify the BEGIN tool the procedure where it begins, in our case, tells us that from here begins the solution to the problem, this tool should be placed in the left margin of the structure of a logical process.

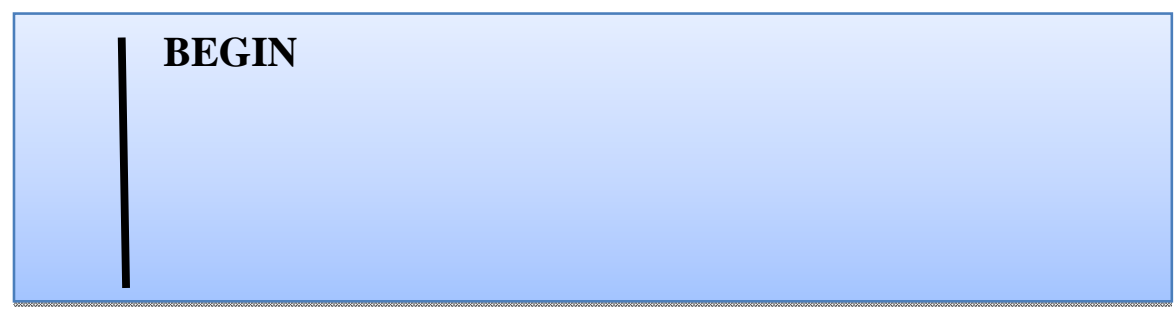

Fig. 2. Format BEGIN tool

2) END tool: In the same way that the BEGIN tool in any process, you always have to specify where the procedure ends, in our case, the END tool, indicates that here ended the solution to the problem, this tool should be placed in the margin left of the structure of a logical process.

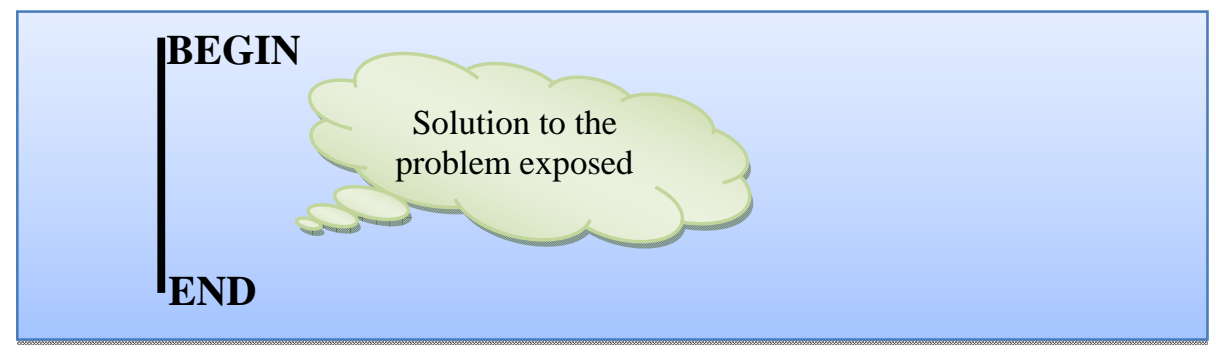

Fig. 3. Format END tool

3) VARIABLE tool: The information will make processed, can be entered in two ways, first by entering the keyboard (Fig. 4), and; the second giving an initial process variable (Fig. 5), in the first case value when only a variable name is placed, indicates that it will perform data entry via keyboard and / or any other device . This tool should be placed in the margin solution.

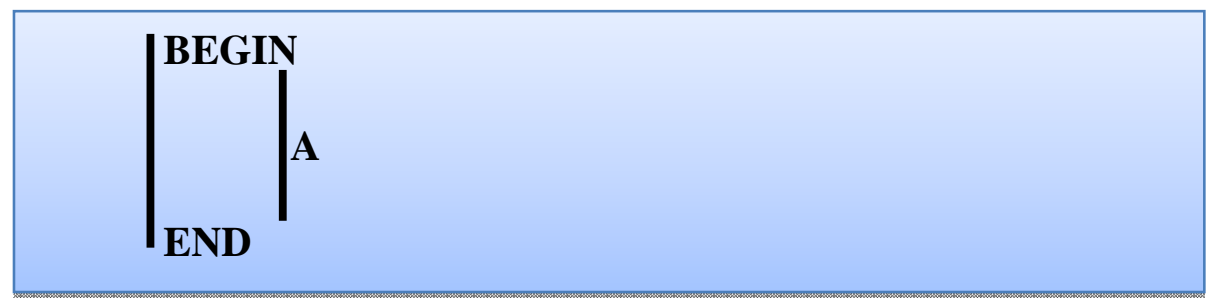

Fig. 4. Format VARIABLE tool (1)

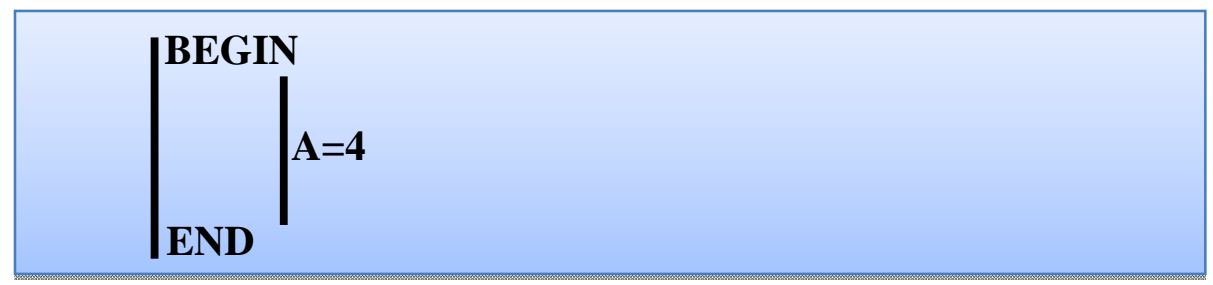

Fig. 5. Format VARIABLE tool (2)

4) OPERATION tool: The information entered by any input device, or; assigned an initial value can be processed in different ways when processing the case of a mathematical operation to use the following flow chart: this tool should be placed in the margin solution. 


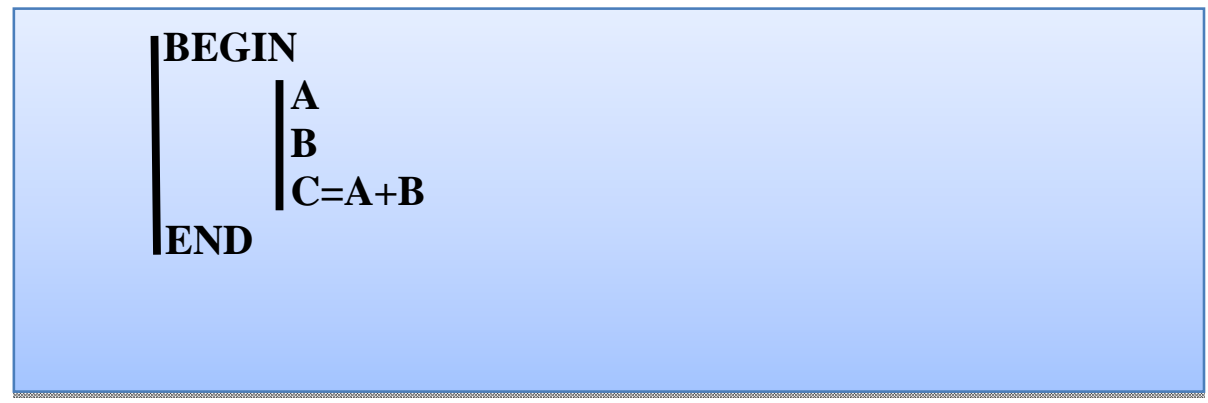

Fig. 6. Format OPERATION tool (1)

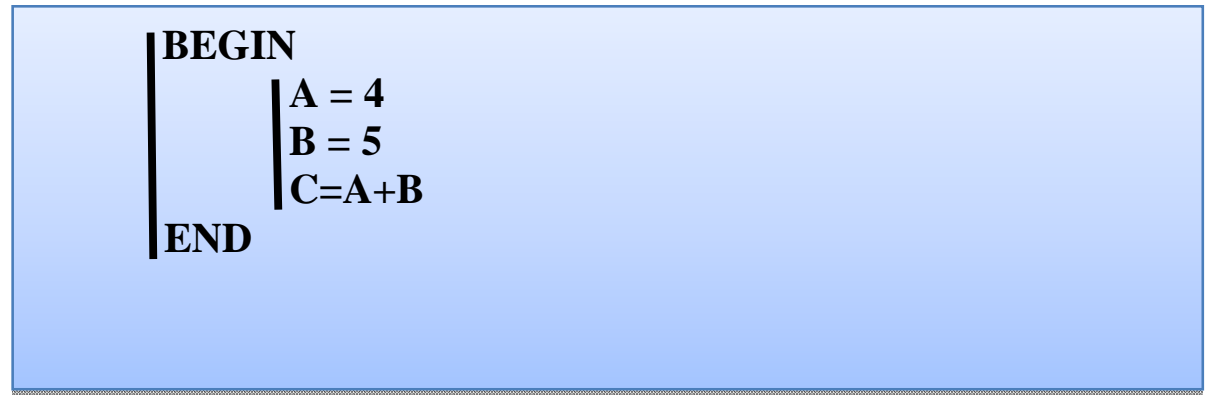

Fig. 7. Format OPERATION tool (2)

TABLE I. FORMAT BASIC MATHEMATICAL OPERATION

\begin{tabular}{|l|l|}
\hline SUM & $\mathrm{C}=\mathrm{A}+\mathrm{B}$ \\
\hline SUBTRACT & $\mathrm{C}=\mathrm{A}-\mathrm{B}$ \\
\hline MULTIPLY & $\mathrm{C}=\mathrm{A}^{*} \mathrm{~B}$ \\
\hline DIVIDE & $\mathrm{C}=\mathrm{A} / \mathrm{B}$ \\
\hline ROOT N & $\mathrm{C}=$ ROOT2(A) \\
\hline POTENCY N & $\mathrm{C}=$ POTENCY4(A) \\
\hline
\end{tabular}

5) Tool \{ \}: This \{\} tool indicates to be present or display on screen variables, outcome variables or messages. To display variables or display results, place the variable (s) within the braces (Fig. 8), and; when you want to display messages, you must get the message enclosed in quotation marks within the braces.

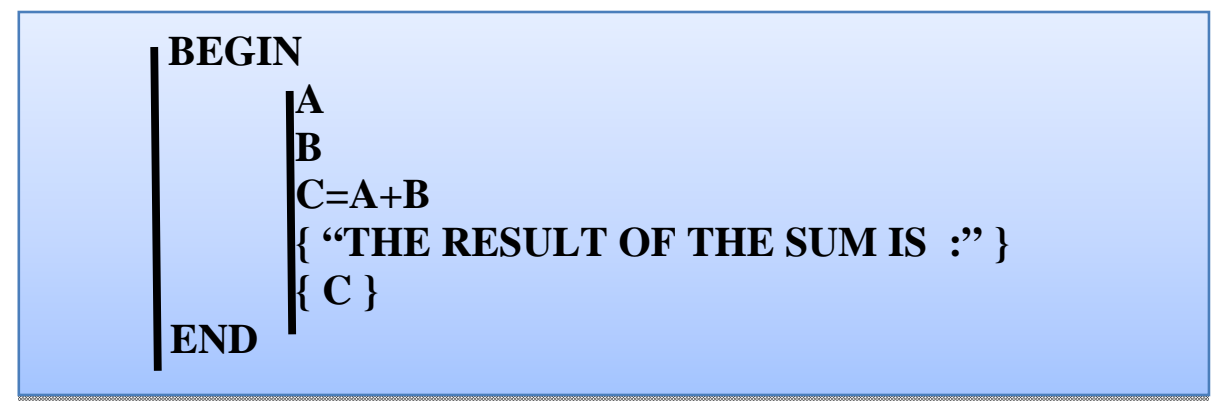

Fig. 8. Format \{\} 
6) Conditional tool: This It allows a question.
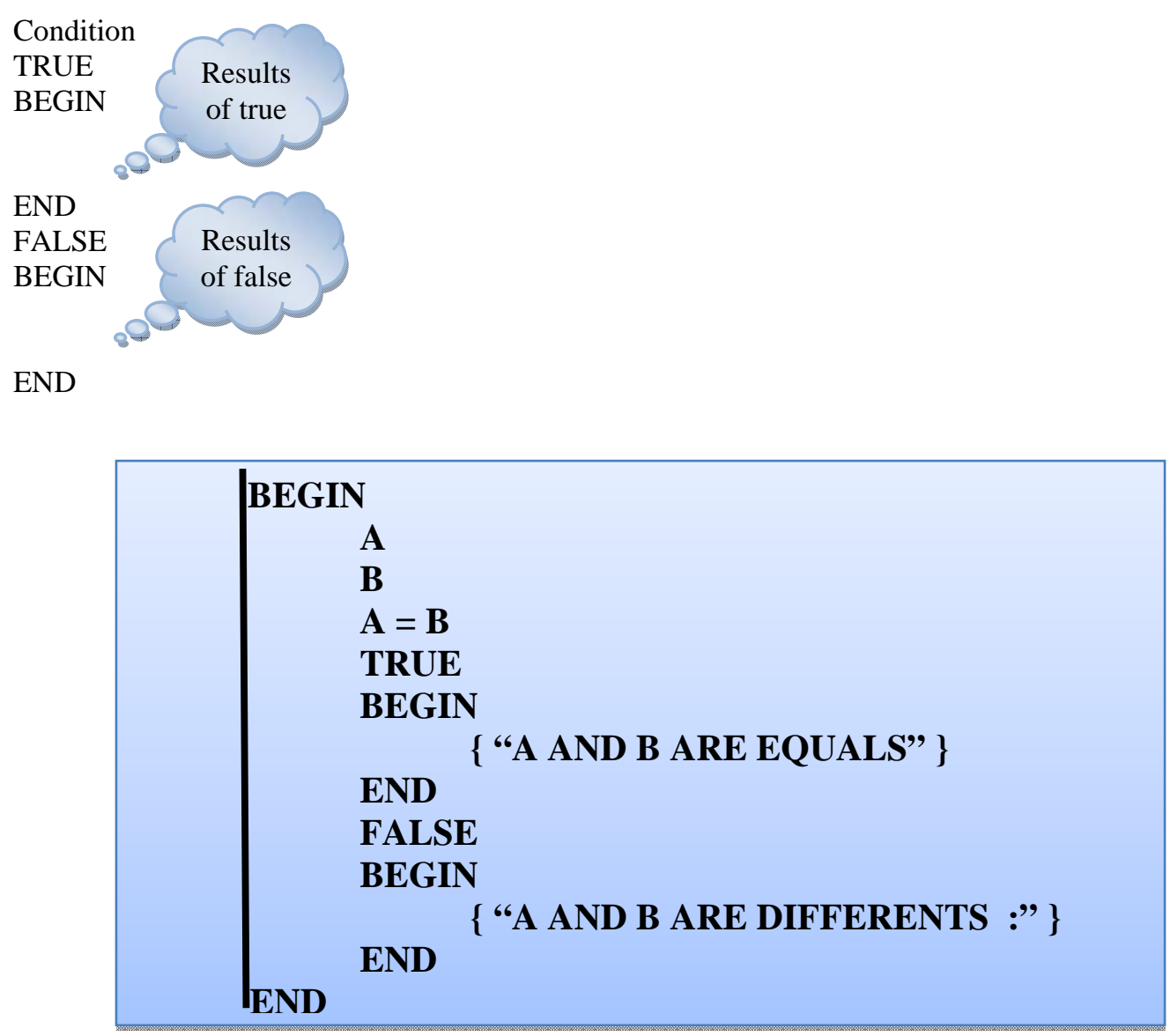

Fig. 9. Format Conditional tool

7) Automatic loop tool: When you need to perform repeat process, you use the automatic loop tool, the process is based on a formula, the same is composed VARIABLE = initial value, final value, increased.

VARIABLE = initial value, final value, increased

BEGIN

PROCESS TO REPEAT

END

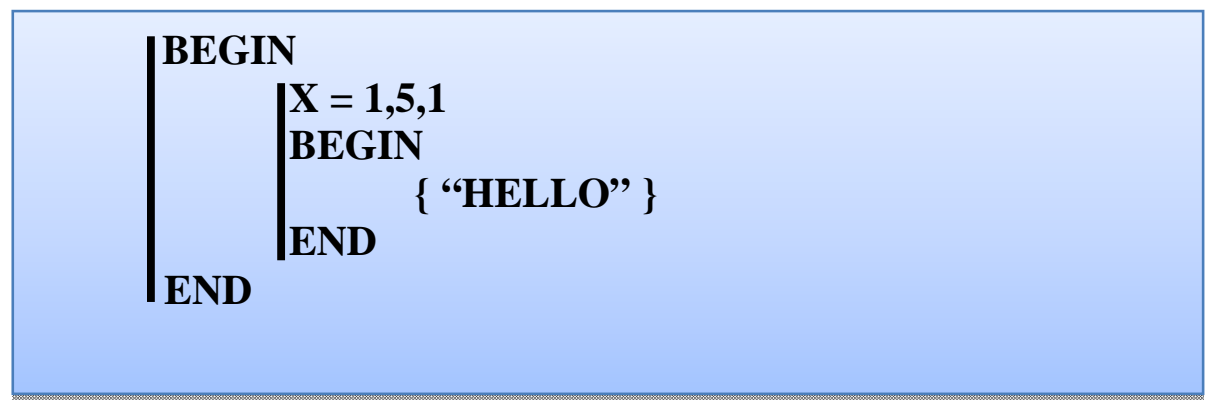

Fig. 10. Automatic loop tool

8) Conditional loop tool: When you need to perform repeat processes, use the conditional loop tool, the process is based on a condition, it must be formulated to result in a truth, and proceed with the process to be repeated addition; within the structure of repetition should be a distorter, so that the variable is conditioned this constantly changing to exit the structure of repetition, repetition otherwise be infinite. 


\section{ASSIGNMENT}

\section{CONDITION}

START

PROCESS (ES) TO REPEAT

Distort

FINISH

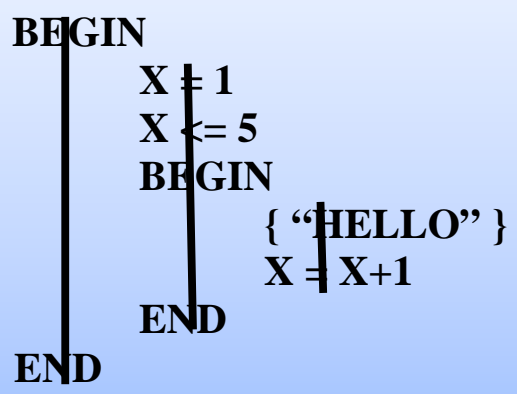

Fig. 11. Conditional loop tool

9) Tool (IPE) "INTEGER PART TRUNC": It allows truncating the integer part of a decimal.

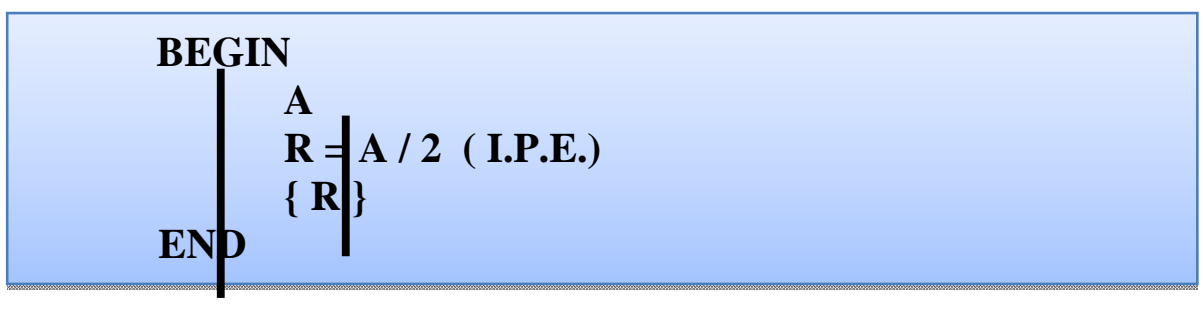

Fig. 12. Tool (IPE) Whole part trunc

10) Tool (DM) It allows for the remainder of a division: It allows for the remainder of a division.

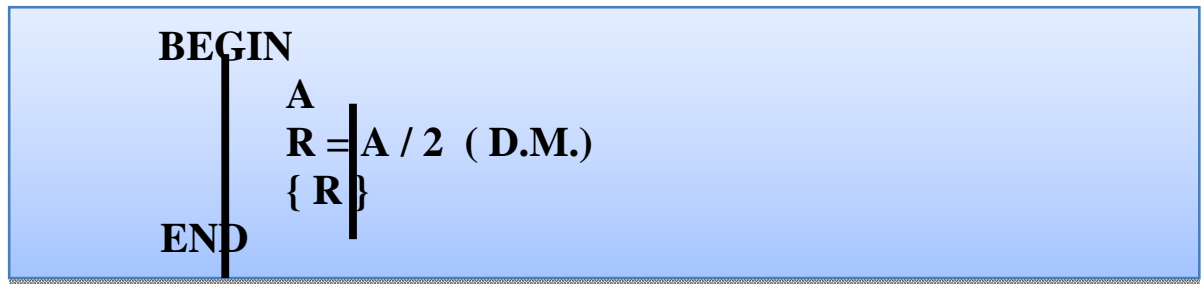

Fig. 13. Tool (DM) It allows for the remainder of a division

VIII.RESULTS

The neuro-cognitive didactic called logical process, methodology permitted to activate the neuronal sensory system based on critical analysis, one of the most valuable components in the neurosensory system of students, encouraging the development of creativity and the ability to integrate cognitive with multiple intelligences, primary structure in solving problems, methodological strategy that ensures meaningful learning.

Students were able to generate significant learning in programming logic.

Program was implemented in PYTHON and JAVA, in order to validate the efficiency of neuro-cognitive educational proposal called logical process. 


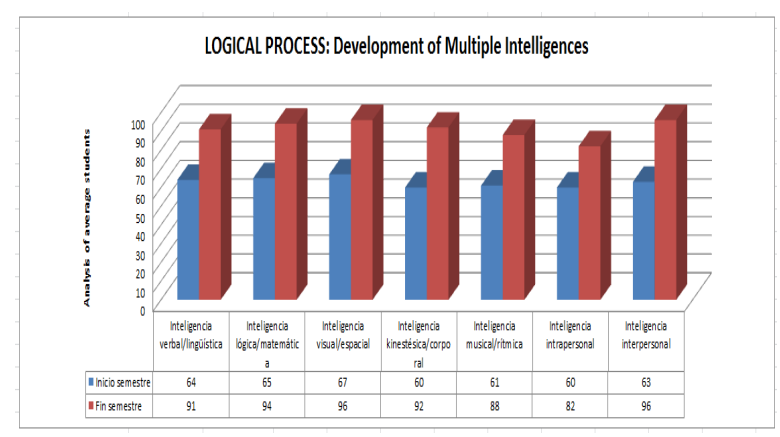

Fig. 14. Analysis of the development of Multiple Intelligences

A descriptive statistical analysis was performed before and after implementation of neuro-cognitive process didactic logical process, students of the first semester of the course of Computer Engineering I Career Mechatronics Engineering International University of Ecuador in the semester in October to March 2017, with a course of 23 students, generating an average for each identified intelligence, validating the efficiency and effectiveness of neuro-cognitive teaching logical process model.

These results confirm the effectiveness of the proposed methodology logical process, implemented in the laboratories of the Faculty of Mechatronics Engineering International University of Ecuador UIDE in the half March to July 2016, the prospects of the project is implemented in all universities of Ecuador and propose as knowledge transfer internationally.

When working with students of the first half of Mechatronics Engineering, it has identified a clear result, positively contributing to higher education to generate significant learning through an innovative methodology, and validated using programming languages that guarantee the effectiveness of the proposed methodology.

At the beginning of the semester the Multiple Intelligences initials involved are evaluated using an analytical system for the recognition of Multiple Intelligences, resulting in low to start the semester percentages, and generating positive end of the semester percentages, this statement is reflected in Table 2, where the descriptive evaluation is characterized by each of the referenced intelligences.

TABLE II

DESCRIPTIVE ASSESSMENT OF THE DEVELOPMENT OF MULTIPLE INTELLIGENCES

\begin{tabular}{|l|r|r|}
\hline \multicolumn{1}{|c|}{ MULTIPLE INTELLIGENCES } & SEMESTER START & END SEMESTER \\
\hline Verbal intelligence/linguistic & $64 \%$ & $91 \%$ \\
\hline Logical intelligence/math & $65 \%$ & $94 \%$ \\
\hline Visual intelligence/espacial & $67 \%$ & $96 \%$ \\
\hline kinesthetic intelligence/bodily & $60 \%$ & $92 \%$ \\
\hline Musical intelligence/rhythmic & $61 \%$ & $88 \%$ \\
\hline Intrapersonal intelligence & $60 \%$ & $82 \%$ \\
\hline Interpersonal intelligence & $63 \%$ & $96 \%$ \\
\hline
\end{tabular}

\section{CONCLUSIONS}

This didactic methodology called logical process, is working with students in the I semester of Mechatronics Engineering International University of Ecuador, with positive results in regard to structure logical solutions conceptualized from the neuro-cognitive structure, getting the reactivation significant, playful and showing that for its versatility, ease and clarity of expression is an easy application process learning.With this new educational goals at a higher level is achieved, and that implementing new knowledge as neuro-cognitive, pedagogical or andragogical strategy is creating environments of modern learning, allowing the generation of images or neuro-cognitive maps brain in individuals who are technical activities involved in solving problems applied within the Engineering in Mechatronics, and promote the development of cognitive and communicative processes.

To conclude, we can not create something before perfectly control the most important tools in the field we work: Mechatronics Engineering, and the method proposed in this research called logical process as a whole has a set of logical tools well defined that allow characterize any logical solution.This teaching methodology of neuro-cognitive development develops skills of critical thinking and fits the type of immediate response required in visual and spatial orientation processes. 


\section{Future Contributions}

After this first stage of research, it is proposed to make an artificial intelligence - oriented study; that is, all the logical process that is performed manually, can be designed and implemented as an expert system.

\section{REFERENCES}

[1] García Trevijano, C., El arte de la lógica, Tecnos, Madrid, 1993.

[2] Fodor, J.A.(1986):La Explicación Psicológica.

[3] Ouillian, R. (1968): “Semantic Memory”, en Semantic Information Processsing (M.Minsky,ed.), MIT Press

[4] Robinson, J.A.(1979):Logic form and Function, Edinburgh U.P.

[5] Davenport, L. (1999). Working Knowledge: How organizations manage what they know. Hardvard Business Scholl Press. Boston, Massachussets.

[6] Fontcuberta, M. (2003). Medios de comunicación y gestión del conocimiento. Revista Iberoamericana de Educación, (32). (En línea).

[7] Koulopoulos, Thomas M y Frappaolo, Carl. Lo fundamental y lo Más Efectivo acerca de la Gerencia del Conocimiento. Editorial Mc Graw Hill. Santa fe de Bogotá. Colombia. 2002.

[8] Lombardo, Enríquez Juan Manuel. y SAIZ, Álvarez José Manuel. (2005) Gestión Creativa e Innovación como fórmula en la Economía del Conocimiento: Centros de Desarrollo Tecnológico. Documento de Trabajo. Proyecto de Investigación Internacional. Universidad Pontificia de Salamanca. Madrid.

[9] Martínez M., M. (2005). Comportamiento humano: Nuevos métodos de investigación. (2da ed.). México: Trillas.

[10] Martínez, A.B. y Fernández, (2005). Internet: Comunicación virtual y desarrollo de habilidades cognitivas. Anuario ININCO. Investigaciones de la comunicación, 2 (13), 39-56.

[11] Mayora C., F. Y Rangel, P.J. (2004, noviembre 15). Aprendizaje colaborativo: Una vía para la producción de conocimiento en la transformación de la Educación Superior. LIV Convención Anual de la Asociación Venezolana para el Avance de la Ciencia (AsoVAC). Universidad de Carabobo. Valencia, Edo. Carabobo.

[12] Molina, José Luis. y Monserrat, Marsal Serra. (2000) La Gestión del Conocimiento en las Organizaciones. Libros en Red.com. Barcelona.

[13] Nonaka, I y Takeuchi (1995): The knowledge creating Company, Oxford. Oxford University Press.

[14] Rangel, P.J. (2005). Aprendizaje de la investigación y gestión del conocimiento en entornos Virtuales. Paradigma. (En prensa). 